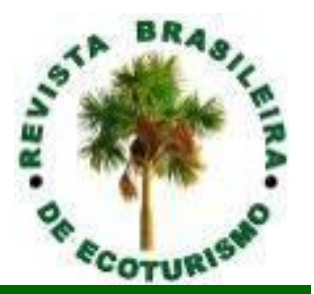

\title{
Condutores de visitantes de Jamaraquá - FLONA do Tapajós, Belterra (PA): características socioeconômicas, acadêmicas e profissionais
}

\section{Visitors Conductors from Jamaraquá - FLONA do Tapajós, Belterra (PA, Brazil): socioeconomic, academic and professional characteristics}

\author{
Simone Lobato Ferreira da Cruz
}

\begin{abstract}
RESUMO: A condução de visitantes em Unidades de Conservação é de suma importância para o desenvolvimento do turismo sustentável nessas áreas protegidas. Este estudo é uma pesquisa de natureza exploratória com abordagem qualitativa - quantitativa e demonstra as características socioeconômicas, acadêmicas e profissionais dos condutores de visitantes da comunidade de Jamaraquá, localizada na Floresta Nacional do Tapajós, município de Belterra (PA). Como instrumento de coleta de dados foi utilizada a entrevista presencial utilizando 17 questionários com modelo baseado em Cotes et al. (2018b), contendo 20 perguntas abertas e fechadas divididas em dois grupos: I- Características sociodemográficas com 06 questões, e IICaracterísticas acadêmicas e profissionais dos condutores, contendo 14. Os resultados incluem a maioria dos condutores de visitantes como sendo do sexo masculino, casados ou em união estável, possuindo o ensino fundamental, com menos de dez anos de experiência na atividade, e ganhando até um salário-mínimo, indicando que seu trabalho serve para o divertimento e a educação dos turistas.
\end{abstract}

PALAVRAS-CHAVE: Condutores de Visitantes; Unidades de Conservação; Ecoturismo; Floresta Nacional do Tapajós; Comunidade de Jamaraquá.

ABSTRACT: The conduction of visitors in Conservation Units is of paramount importance for the development of sustainable tourism in these protected areas. This study is an exploratory research with a qualitative-quantitative approach and demonstrates the socioeconomic, academic and professional characteristics of the conductors of community visitors from Jamaraquá, located in the Tapajós National Forest, municipality of Belterra (PA, Brazil). Data was collected through a face-to-face interview that used 17 questionnaires with a model based on Cotes et al. (2018b), containing 20 questions, both open and closed, divided into two groups: I-Sociodemographic characteristics with 06 questions, and II- Academic and professional characteristics of the conductors, containing 14. The results include the majority of the conductors of visitors as being male, married or in a stable union, having elementary education, with less than ten years of experience in the area, and earning up to a minimum wage, pointing that their work is for the entertainment and education of tourists.

KEYWORDS: Visitors Conductors; Conservation Units; Ecotourism; Tapajós National Forest; Jamaraquá Community. 


\section{Introdução}

No Brasil, as Unidades de Conservação (UCs) foram criadas no intuito de conter os avanços de ocupação desenfreada do território e de uso negligente dos recursos naturais, porém tornaram-se importantes atrativos para turistas interessados em atividades que valorizam a atividade física e as práticas ambientais, acompanhando uma tendência mundial que se mostra presente desde as últimas décadas do século $X X$ até os dias atuais, segundo a United Nations Environment Program (UNEP, 2011). Nesse direcionamento contemporâneo do turismo, os turistas estão interessados em práticas que unam o desenvolvimento econômico à conservação ambiental, assim como também ao equilíbrio social, o chamado turismo sustentável (PRADO et al., 2004; KINKER, 2002).

Segundo a Organização Mundial do Turismo (OMT) o turismo sustentável é aquele que considera os seus impactos econômicos, sociais e ambientais atuais e futuros, atendendo às exigências dos visitantes, da indústria, do meio ambiente e das comunidades anfitriãs (OMT, 2018).

Diante disso, o Ecoturismo surgiu como um segmento da atividade turística que incorpora os preceitos da sustentabilidade, traduzindo-se em viagens responsáveis que objetivam o contato com a natureza, e 0 comprometimento do viajante em relação à conservação do ambiente, além da promoção do bem-estar da comunidade visitada (WESTERN, 2002). Nesse âmbito, as áreas protegidas agrupam uma grande diversidade de recursos, o que se constitui em grande atrativo para ecoturistas, tornando-as fortemente promissoras para a atividade (BRASIL 2010).

O Sistema Nacional de Unidades de Conservação da Natureza (SNUC), criado a partir da Lei no 9.985 em 18 de julho de 2000, estabelece em seu capítulo II, artigo 4ํㅜㄹ parágrafo XII como um dos objetivos das unidades de conservação "favorecer condições e promover a educação e interpretação ambiental, a recreação em contato com a natureza e o turismo ecológico". Também aponta que as categorias de áreas protegidas que permitem a visitação pública são: Parque Nacional, Monumento Natural, Refúgio de Vida Silvestre, Área de Proteção Ambiental, Floresta Nacional, Reserva Extrativista, Reserva de Fauna, Reserva de Desenvolvimento Sustentável e Reserva Particular do Patrimônio Natural, sendo exigido o cumprimento de normas e restrições estabelecidas no Plano de Manejo da unidade ou regulamento específico (BRASIL, 2000).

Devido ao grande interesse, o fluxo de turistas em UCs aumentou progressivamente no decorrer dos anos, o que fez com que as atividades de Ecoturismo se tornassem práticas frequentes nessas áreas, ocasionando alguns impactos ambientais negativos e acidentes com turistas, especialmente em parques estaduais e federais, onde era permitida a entrada desordenada e sem acompanhamento (CEBALLOS-LASCURÁIN, 2002); (BRASIL, 2010); (IKEMOTO et al., 2009); (BOGGIANI, 2018); (SILVA; MAIA, 2011).

Diante disso, houve a necessidade de se fazer o acompanhamento de visitantes nas Unidades de Conservação, que se iniciou a partir da contratação de indivíduos locais, que gradativamente começaram a se identificar como monitores ou guias, ocasionando uma organização maior da atividade, tornando-se obrigatória a presença de guiamento nas visitações em 
alguns parques (BOGGIANI, 2018). O profissional desta área tem a função de repassar as informações do local visitado, ajudando na educação ambiental, e proporcionando aos indivíduos uma maior segurança, informações sobre a história da unidade, além de aspectos culturais, o que resulta em uma experiência mais completa para aqueles interessados em atividades em meio à natureza, mais especificamente na caminhada em trilhas de longa duração (RIBAS; HICKENBICK, 2012; PEREIRA et al., 2015; NEIMAN, 2007).

Sob a perspectiva sustentável da atividade turística, o condutor de visitantes é um componente essencial, pois ao mesmo tempo em que cumpre as finalidades educativas do visitante e auxilia na conservação da localidade, também torna possível a geração de emprego e renda para moradores da região.

Canto-Silva e Silva (2017) afirmam que é importante que se façam pesquisas acerca da identificação do perfil, necessidades e limitações desses profissionais, para que seja melhorada a qualidade de vida dos mesmos e os serviços de visitação oferecidos nas UCs.

Apesar da relevância da atuação desses profissionais, tanto na sustentabilidade ambiental, quanto no desenvolvimento das comunidades locais, é possível perceber que temas referentes aos mesmos ainda são pouco explorados, principalmente no que se refere à condução turística em Florestas Nacionais.

Assim, pretendeu-se saber: Como vivem os condutores de visitantes atuantes na comunidade de Jamaraquá? Como é a sua formação acadêmica? Qual sua opinião acerca da atividade em que atuam?

A partir dessas questões, o presente estudo tem como objetivo geral demonstrar características socioeconômicas, acadêmicas e profissionais dos condutores de visitantes da comunidade de Jamaraquá , localizada na Floresta Nacional do Tapajós, município de Belterra - PA. Para tal fim, tem como objetivos específicos: a) identificar o informações socioeconômicas dos condutores b) Averiguar dados acadêmicos; c) Conhecer aspectos profissionais e d) Pesquisar a opinião dos entrevistados sobre a atividade que desempenham.

\section{Referencial Teórico}

\section{As Florestas Nacionais e o Ecoturismo}

As Florestas Nacionais (FLONAS) pertencem ao grupo de unidades de conservação de uso sustentável estabelecido pela Lei no 9.985 , e são definidas como áreas com cobertura florestal de espécies predominantemente nativas, tendo por objetivo principal o uso múltiplo sustentável de recursos florestais e a pesquisa científica, com destaque para procedimentos de exploração sustentável de florestas nativas. Admitem a permanência de populações tradicionais habitantes da área desde a sua criação, assim como também a visitação pública, obedecendo às normas estabelecidas pela instituição responsável pela sua administração, e pelo Plano de Manejo da unidade (BRASIL, 2000). Nesse contexto, a visitação pública é um importante meio para que a UC amplie seus recursos econômicos, aproximando natureza e sociedade, impulsionando sua manutenção e utilização sustentável (BRASIL, 2005). O uso público através da visitação é ligado diretamente às 
atividades de educação, interpretação ambiental, esportes, recreação, ciência e lazer. Por meio delas, o visitante tem a oportunidade de conhecer, entender e dar valor aos recursos naturais e culturais existentes nas áreas protegidas (BRASIL, 2000; BRASIL, 2005; BRASIL, 2006). Por isso, esses locais têm se apresentado como um ambiente exemplar para a prática do Ecoturismo, existindo sempre a obrigatoriedade de disponibilizar estruturas e ofertas apropriadas, seguindo normas e certificações padronizadas de segurança e qualidade atestadas internacionalmente, além da observância dos princípios de conservação (BRASIL, 2010; VERÍSSIMO et al., 2011).

No segmento de Ecoturismo são atividades habituais: a observação astronômica, de fauna, flora, formações geológicas, espeleoturismo, caminhadas, safáris fotográficos, trilhas interpretativas, mergulho livre, acampamentos, visitação a sítios arqueológicos e às comunidades receptoras, dentre outras (BRASIL, 2010). No caso específico de visitas a populações residentes em áreas protegidas, é praticada uma interface do Ecoturismo onde existe uma dimensão social maior, o chamado Turismo de base Comunitária (TBC) (WWF, 2001). Nesse caso, quem protagoniza a gestão da visitação é a própria comunidade local, o que resulta na geração de vantagens coletivas, proporcionando qualidade de vida, experiência multicultural, valorização da cultura e da história dessas populações, assim como também o uso sustentável dos recursos da Unidade de Conservação (BRASIL, 2019).Dessa forma, esse tipo de turismo tem a característica de transformação social das comunidades, na medida em que elas assumem o poder para desempenhar função ativa e criativa no planejamento de seu próprio futuro (SACHS, 2008). Em relação ao público consumidor, é destinado a grupos pequenos de pessoas interessadas em vivências originais e enriquecedoras, oferecendo a conjunção de experiências culturais legítimas com magníficas paisagens naturais (MALDONADO, 2009).

\section{A Floresta Nacional do Tapajós e o turismo de base comunitária}

A Floresta Nacional do Tapajós foi criada através do decreto N ․ㅜ 73.684 publicado em 20 de fevereiro do ano de 1974 e está localizada no Oeste do Estado do Pará, região do baixo Amazonas, na zona de floresta ombrófila densa de terras baixas. Atualmente, possui uma área de 527.319 hectares, englobando os municípios de Aveiro, Belterra, Placas e Rurópolis. Tem acesso pelo rio Tapajós e pela Rodovia BR-163, que liga Cuiabá a Santarém. Vivem na Unidade cerca de 1.050 famílias, divididas em localidades assentadas pelo Instituto Nacional de Colonização e Reforma Agrária INCRA, formadas por posseiros e proprietários dessas terras, encontrados no curso da rodovia BR-163; e em 23 comunidades e três aldeias indígenas da etnia Munduruku, estabelecidas ao longo dos rios Tapajós e Cupari, totalizando em torno de quatro mil pessoas. São elas: Acaratinga, Jaguarari, Pedreira, Bom Jesus, Piquiatuba, Marituba, Nazaré, Bragança, Novo Marai, Marai, Pini, Tauari, Chibé, Takuara, Prainha I, Prainha II, Itapaiúna, Paraíso, Jutuarana, Itapuama, São Francisco das Chagas, São Francisco do Godinho, Uruará, São Domingos, Maguari e Jamaraquá (BRASIL, 1974); (BRASIL, 2003); (ESPÍNOLA; CASTRO, 2012; BRASIL, 2021).

Em relação ao potencial econômico, as comunidades da UC possuem várias particularidades para serem exploradas de diversas formas, servindo 
como um modelo em organização comunitária, onde as populações locais estão à frente de uma série de atividades, como agricultura familiar, extrativismo, pesca e caça. Porém, o Ecoturismo e o TBC destacam-se principalmente nas comunidades de São Domingos, Maguari e Jamaraquá, que possuem fácil acesso através de estrada e rio, e têm sido as mais requisitadas por visitantes nacionais e estrangeiros, oferecendo uma demonstração da vida amazônica, por meio de atrativos como floresta preservada, igarapés, rio, vida selvagem e cultura ribeirinha (MOREIRA; BURNS, 2015; BRASIL, 2019a). Através desses atrativos são desenvolvidas atividades como caminhadas em trilhas interpretativas, visitações em praias, apreciação da culinária regional, convivência com o cotidiano local, turismo de aventura e turismo científico. (BRASIL 2019a; BRASIL, 2021).

Vale ressaltar que o TBC é apontado no Plano de Manejo como um dos objetivos estratégicos do Programa de Uso Público da referida área, tendo inclusive a função de valorizar as tradições locais. É um dos principais pontos de trabalho em execução atualmente, com a elaboração do ordenamento das atividades turísticas da UC, incluindo o mapeamento das trilhas, elaboração do Plano de Uso Público, o reexame do regimento interno dos condutores e a preparação de portaria com metodologia e regras para a atividade de condução (BRASIL, 2019a; BRASIL, 2019b).

\section{Algumas considerações sobre a condução de visitantes}

A profissão de condutor ambiental surgiu baseada nos objetivos de desenvolvimento da prática do turismo sustentável, apoiando a educação ambiental dos visitantes e buscando o cumprimento da quebra de modelos de exclusão. Assim, considerou-se o método de unir os saberes e fazeres dos habitantes das Unidades de Conservação e seu entorno, dando oportunidades de trabalho e renda, melhorando assim as condições de vulnerabilidade social em que normalmente se encontram esses indivíduos (CUNHA et al., 2016).

$\mathrm{Na}$ condução em ambientes naturais existem três possibilidades de atuação: o condutor de turismo de aventura, o guia de turismo especializado em atrativo natural e por fim, o condutor ambiental local, geralmente chamado de condutor local (CANTO-SILVA et al.,2015).

A atividade foi normatizada pelo Instituto Chico Mendes de Conservação da Biodiversidade (ICMBIO) através da Instrução Normativa no 08 de 18 de setembro de 2008, onde estão "normas e procedimentos para a prestação de serviços vinculados à visitação e ao turismo em Unidades de Conservação Federais por condutores de visitantes" (BRASIL, 2008). Com a publicação da portaria no 27 de 30 de janeiro de 2014 do Ministério do Turismo, que trata dos requisitos e critérios para o guiamento turístico, houve a diferenciação entre o trabalho do condutor de visitantes, do guia e do monitor de Turismo, o que está determinado no seu artigo oitavo. Através desse documento, as particularidades locais dos atrativos foram mais valorizadas, assim como também a figura do condutor local, que deve trabalhar de forma complementar com o guia de turismo (BRASIL, 2014).

Em três de maio de 2016 foi publicada a Instrução Normativa ICMBIO no 2, que substituiu a Instrução normativa no $08 / 2008$, e tratou sobre as "normas e procedimentos administrativos para autorização de uso para a 
prestação do serviço de condução de visitantes em unidades de conservação federais". No documento, o condutor de visitantes é conceituado em seu artigo $2^{\circ}$, inciso I, como:

Pessoa física autorizada pelo Instituto Chico Mendes a atuar na condução de visitantes na unidade de conservação, desenvolvendo atividades informativas e interpretativas sobre o ambiente natural e cultural visitado, além de contribuir para o monitoramento dos impactos socioambientais nos sítios de visitação (BRASIL, 2016).

Além disso, o documento estabeleceu que a atuação como condutor de visitantes seja restrita à indivíduos autorizados pela administração da UC, sob condições de portaria específica, e que preferencialmente seja realizada por habitantes do interior ou do entorno das áreas de proteção, de acordo com a categoria de manejo (NASCIMENTO et al., 2016).

\section{Material e métodos}

\section{Área de estudo}

O trabalho foi realizado na comunidade de Jamaraquá, localizada à margem direita do Rio Tapajós, na porção norte da Floresta Nacional do Tapajós, município de Belterra, no estado do Pará. O local está a 25 km de distância do centro urbano de Belterra, e a $75 \mathrm{~km}$ da cidade de Santarém (SILVA et al., 2017) (Figura 1).

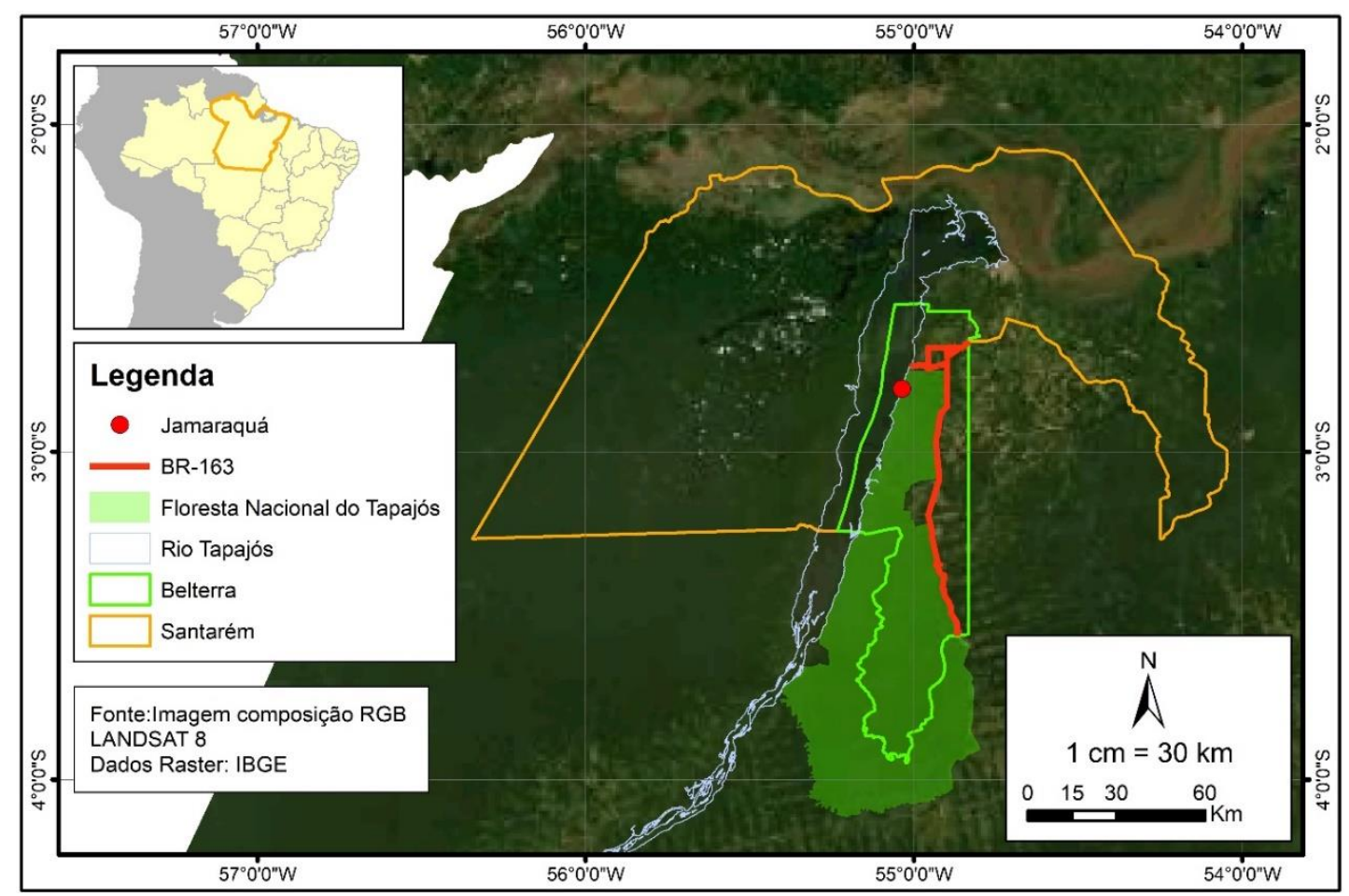

Figura 1: Mapa de localização da comunidade de Jamaraquá.

Figure 1: Location map of the Jamaraquá community.

Fonte: Elaborado por Matos (2021).

Source: Elaborated by Matos (2021). 
A comunidade foi criada em 1974 e possui sua representação jurídica na Floresta Nacional do Tapajós através da Associação de Moradores de Jamaraquá (ASMORJA) (INEA, 2012). Na comunidade residem cerca de 26 famílias totalizando 103 pessoas (SILVA et al., 2014).

A maioria dos moradores da localidade habita em residências construídas em madeira e cobertas com palhas, reproduzindo aspectos típicos da arquitetura regional, e têm o seu cotidiano influenciado pelos movimentos das águas do Rio Tapajós. A energia elétrica é fornecida através da rede pública, e a sua economia é baseada em atividades como agricultura, pesca e extrativismo, destacando-se o manejo adequado da seringueira (hevea brasilienses) e o artesanato produzido com o látex, de onde são produzidas várias peças com borracha natural colorida, encontradas na loja existente no centro da comunidade. Também são comercializados no local, outros vários produtos como o óleo de Andiroba (Carapa Guianensis Aubl.), mel de abelha, leite de Sucuba (Himatanthus sucuuba), objetos de madeira, plantas ornamentais e polpas de frutas, além dos artigos feitos de palha e as biojóias (FERRAZ; SAMPAIO, 1996; CASTILLO et al., 2007; BEZERRA; PINTO 2018; MOREIRA; BURNS, 2015; BRASIL, 2021).

O Turismo de Base Comunitária se destaca como a principal fonte de renda dos habitantes de Jamaraquá, e teve seu início de forma embrionária, no ano de 1995, através da organização não governamental Saúde e Alegria. A atividade foi aprovada para a comunidade no ano de 2000, por meio do Promanejo, projeto desenvolvido pelo Instituto Brasileiro do Meio Ambiente (IBAMA), que envolveu diversos projetos feitos pelas comunidades da Floresta Nacional do Tapajós. A partir de 2005, houve uma organização maior da atividade com a formação de uma associação e de roteiros turísticos no interior da floresta, gerando rendimentos através de visitações à comunidade, sobretudo em caminhadas nas trilhas que levam até a Samaúma (Ceiba pentandra) (BEZERRA; PINTO 2018).

Baseada em vários atrativos naturais e culturais típicos da Amazônia, a comunidade oferece atualmente uma série de atividades para os turistas, como caminhadas guiadas em trilhas com pernoite na floresta, cortes de seringa, passeios diurnos de canoa no igapó e rio Tapajós e noturnos para focagem de Jacaré, banho de Igarapé e visualização de peixes ornamentais, visita à casa de farinha, procissão de São Benedito, dentre outros. Quanto à hospedagem dos visitantes, a comunidade oferece pousadas simples e redários, além de pequenos restaurantes coordenados por membros da comunidade, que servem comidas típicas da região (BRASIL, 2021).

\section{Amostragem de dados}

O presente estudo é uma pesquisa de natureza exploratória, a qual tem como objetivo principal o desenvolvimento, esclarecimento e modificação de conceitos e ideias, tendo em vista a formulação de problemas mais precisos ou hipóteses pesquisáveis para estudos posteriores (GIL, 2006).

A abordagem é qualitativa - quantitativa, que são conceituadas como verificações de pesquisa baseadas na experiência, cujo objetivo é descrever ou analisar fatos, avaliar programas ou isolar variáveis-chave. Descrevem as circunstâncias valendo-se de critérios quantitativos que situam proporções e 
correspondências entre as variáveis observadas, buscando elementos que permitam a comprovação das teorias. Utilizam como técnica de coleta de dados, as entrevistas pessoais, questionários e procedimentos de amostragem (MIRANDA, 2004).

Quanto aos procedimentos, o trabalho foi iniciado através de pesquisa bibliográfica, com dados coletados de publicações em meio digital, documentos, livros e legislação específica sobre o tema. Essa categoria de pesquisa é aquela elaborada com base em material já organizado, encontrado basicamente em livros, artigos científicos e documentos. Contou também com um estudo de campo, que é caracterizado pela coleta de dados junto à indivíduos, com o recurso de diferentes tipos de pesquisa (GIL ,2006; FONSECA, 2002).

A coleta de informações foi realizada através de entrevistas presenciais, realizadas em duas visitas à comunidade, a primeira no mês de outubro de 2019, e a segunda em março de 2020, por meio de 17 questionários com modelo baseado em Cotes et al. (2018b), contendo 20 perguntas abertas e fechadas, divididas em dois grupos: I - Características sociodemográficas com 06 questões, e II - Características acadêmicas e profissionais dos condutores, contendo 14 questionamentos. Posteriormente, os dados obtidos foram tratados com a utilização do programa Excel.

A população da pesquisa é constituída por condutores de visitantes da comunidade de Jamaraquá, dos sexos masculino e feminino, que totalizam 23 indivíduos. Pelo fato de que não tiveram disponibilidade, ou não estavam presentes no momento das entrevistas, a pesquisa abarcou uma amostra de 17 entrevistados, correspondendo a aproximadamente $74 \%$ do número total de profissionais, estando assim, acima do intervalo de confiança apontado por Pinheiro et al. (2006), que é de $68 \%$ para pesquisas da área de ciências sociais, o que foi confirmado pela Equação 1.

$$
\mathrm{n}=\frac{s^{2} \cdot z^{2} \cdot \mathrm{N}}{\left(s^{2} \cdot z^{2}+e^{2}\right) \cdot(\mathrm{N}-1)}
$$

Sendo $n$ o tamanho da amostra; $N$ o tamanho do universo; $S^{2}$ a variância da amostra; $Z$ o desvio padrão relacionado ao intervalo de confiança; e e o valor de tolerância em relação aos resultados da pesquisa (erro amostral).

Quanto aos aspectos éticos, as entrevistas foram realizadas com a permissão dos interrogados por meio do Termo de Consentimento Livre e Esclarecido baseado na Resolução no 196/96, do Conselho Nacional de Saúde, Brasil (2013), que estabelece as diretrizes e normas regulamentadoras de pesquisas envolvendo seres humanos, mantendo-se o anonimato dos mesmos. 


\section{Resultados e Discussão}

Objetivando a análise e demonstração dos resultados obtidos pelos questionários, optou-se por apresentá-los em duas tabelas após a conversão em percentuais. Na primeira, intitulada de Tabela 1, estão os dados relativos às características sociodemográficas dos condutores entrevistados, que identificaram informações referentes ao sexo, idade, estado civil, local de nascimento, local de residência e a forma de posse de suas moradias.

Tabela 1: Características sociodemográficas

Table 1: Sociodemographic characteristics

\begin{tabular}{lccc}
\hline Variável & Categorias & Valor & Percentual \\
\hline \multirow{2}{*}{ Sexo } & Masculino & 15 & $88,2 \%$ \\
& Feminino & 2 & $11,8 \%$ \\
Faixa etária & 20 a 30 anos & 5 & $29,4 \%$ \\
& & & \\
& 31 a 40 anos & 2 & $11,8 \%$ \\
Estado civil & 41 anos ou mais & 10 & $58,8 \%$ \\
& Casado/União Estável & 11 & $64,7 \%$ \\
& Solteiro & 5 & $29,4 \%$ \\
Local de nascimento & Divorciado & 1 & $5,9 \%$ \\
& Jamaraquá & 11 & $64,7 \%$ \\
Local de residência & Piquiatuba (Belterra) & 2 & $11,8 \%$ \\
Tipo de moradia em relação à & Santarém & 2 & $11,8 \%$ \\
posse & Belém & 1 & $5,9 \%$ \\
\hline
\end{tabular}

Fonte: Elaborada pela autora. Source: Prepared by the author

A maior parte da população participante desta pesquisa corresponde ao sexo masculino $(88,2 \%)$, tendo a participação feminina uma porcentagem menor (11,8\%), o que se aproxima da pesquisa feita por Cotes et al. (2018b), onde a porcentagem alcançada foi de $11,4 \%$. Encontram-se em sua maioria na faixa etária compreendida entre 41 anos ou mais $(58,8 \%)$, sendo casados ou em união estável $(64,7 \%)$.

Em relação ao local de nascimento, a maioria nasceu em Jamaraquá $(64,7 \%)$ e reside na comunidade em residência própria (100\%). Sobre o assunto, Ribas e Hickenbick (2012), indicam que o membro da comunidade ou do seu entorno têm a preferência para exercer a atividade de condução de visitantes, pois ao mostrar os conhecimentos vivenciais do meio biológico e cultural que interpreta, é diferenciado dos outros profissionais do mercado turístico, podendo promover um intercâmbio cultural e tornar-se um atrativo a mais para o local.

$\mathrm{Na}$ Tabela 2 estão os resultados referentes às características acadêmicas e profissionais dos condutores. 
Tabela 2: Características acadêmicas e profissionais dos condutores.

Table 2: Academic and professional characteristics of drivers.

\begin{tabular}{|c|c|c|c|}
\hline Variável & Categorias & Valor & Percentual \\
\hline \multirow{4}{*}{ Nível de formação } & Ensino Fundamental & 10 & $58,8 \%$ \\
\hline & Ensino Médio & 5 & $29,4 \%$ \\
\hline & Graduação & 1 & $5,9 \%$ \\
\hline & Pós-Graduação & 1 & $5,9 \%$ \\
\hline \multirow{3}{*}{ Experiência como condutor } & Menos de 10 anos & 8 & $47,1 \%$ \\
\hline & Até 10 anos & 2 & $11,8 \%$ \\
\hline & 11 anos ou mais & 7 & $41,2 \%$ \\
\hline \multirow[b]{2}{*}{ Remuneração como condutor } & Até 1 salário mínimo & 12 & $70,6 \%$ \\
\hline & $\begin{array}{l}\text { Mais de um salário } \\
\text { mínimo }\end{array}$ & 5 & $29,4 \%$ \\
\hline \multirow{14}{*}{$\begin{array}{l}\text { Você possui outra fonte de } \\
\text { renda além do que ganha } \\
\text { como condutor de visitantes? }\end{array}$} & Sim & 14 & $82,4 \%$ \\
\hline & Não & 3 & $17,6 \%$ \\
\hline & $\begin{array}{c}\text { Controlador de micro } \\
\text { sistema de abastecimento } \\
\text { de água }\end{array}$ & 1 & $5,9 \%$ \\
\hline & Bolsa família & 1 & $5,9 \%$ \\
\hline & Trabalho como pedreiro & 1 & $5,9 \%$ \\
\hline & Trabalho como cozinheira & 1 & $5,9 \%$ \\
\hline & $\begin{array}{c}\text { Trabalho como moto } \\
\text { taxista }\end{array}$ & 1 & $5,9 \%$ \\
\hline & Trabalho como artesanato & 2 & $11,8 \%$ \\
\hline & Trabalho com comércio & 2 & $11,8 \%$ \\
\hline & Aposentadoria & 1 & $5,9 \%$ \\
\hline & $\begin{array}{c}\text { Trabalho com extrativismo } \\
\text { e artesanato }\end{array}$ & 1 & $5,9 \%$ \\
\hline & $\begin{array}{c}\text { Trabalho como } \\
\text { extrativismo }\end{array}$ & 1 & $5,9 \%$ \\
\hline & $\begin{array}{c}\text { Trabalho de árbitro de } \\
\text { futebol }\end{array}$ & 1 & $5,9 \%$ \\
\hline & $\begin{array}{c}\text { Trabalho com criação de } \\
\text { galinhas /ajuda em } \\
\text { restaurante }\end{array}$ & 1 & $5,9 \%$ \\
\hline \multirow{2}{*}{$\begin{array}{l}\text { Você fez curso específico de } \\
\text { condutor? }\end{array}$} & Sim & 10 & $58,8 \%$ \\
\hline & Não & 7 & $41,2 \%$ \\
\hline \multirow{6}{*}{$\begin{array}{l}\text { Você fez algum curso de } \\
\text { capacitação na área ambiental } \\
\text { ou do turismo? }\end{array}$} & Sim & 12 & $70,6 \%$ \\
\hline & Não & 5 & $29,4 \%$ \\
\hline & $\begin{array}{l}\text { Coordenador de } \\
\text { comunidade turística }\end{array}$ & 1 & $5,9 \%$ \\
\hline & $\begin{array}{l}\text { Curso de guia } \\
\text { especializado }\end{array}$ & 1 & $5,9 \%$ \\
\hline & $\begin{array}{c}\text { Curso de observação de } \\
\text { animais }\end{array}$ & 1 & $5,9 \%$ \\
\hline & Curso de controle de fogo & 1 & $5,9 \%$ \\
\hline \multirow{2}{*}{$\begin{array}{l}\text { Você fez curso de primeiros } \\
\text { socorros? }\end{array}$} & Sim & 11 & $64,7 \%$ \\
\hline & Não & 6 & $35,3 \%$ \\
\hline
\end{tabular}


...continuação.

\begin{tabular}{|c|c|c|c|}
\hline Variável & Categorias & Valor & Percentual \\
\hline \multirow{5}{*}{ Fala outro idioma? } & Sim & 14 & $82,4 \%$ \\
\hline & Não & 3 & $17,6 \%$ \\
\hline & Inglês e francês & 1 & $5,9 \%$ \\
\hline & Francês e espanhol & 1 & $5,9 \%$ \\
\hline & Inglês & 1 & $5,9 \%$ \\
\hline \multirow{3}{*}{$\begin{array}{l}\text { Em relação a nacionalidade } \\
\text { dos turistas, você atende: }\end{array}$} & $\begin{array}{l}\text { A maioria é de turistas } \\
\text { brasileiros }\end{array}$ & 14 & $82,4 \%$ \\
\hline & $\begin{array}{c}\text { A maioria é de turistas } \\
\text { estrangeiros }\end{array}$ & 1 & $5,9 \%$ \\
\hline & $\begin{array}{c}\text { Atende a mesma } \\
\text { quantidade de turistas } \\
\text { brasileiros e estrangeiros }\end{array}$ & 2 & $11,8 \%$ \\
\hline \multirow[b]{2}{*}{$\begin{array}{l}\text { Sobre a forma de dar } \\
\text { informações aos turistas: }\end{array}$} & $\begin{array}{c}\text { Você espera que eles } \\
\text { perguntem o que querem } \\
\text { saber }\end{array}$ & 2 & $11,8 \%$ \\
\hline & $\begin{array}{c}\text { Você faz uma } \\
\text { apresentação geral sobre } \\
\text { os atrativos durante a } \\
\text { trilha }\end{array}$ & 15 & $88,2 \%$ \\
\hline \multirow{2}{*}{$\begin{array}{l}\text { Você possui domínio da } \\
\text { atividade de condutor? }\end{array}$} & Sim & 15 & $88,2 \%$ \\
\hline & Não & 2 & $11,8 \%$ \\
\hline \multirow{7}{*}{$\begin{array}{l}\text { Qual o período no ano em que } \\
\text { aparecem mais grupos de } \\
\text { turistas para serem guiados? }\end{array}$} & Julho a fevereiro & 5 & $29,4 \%$ \\
\hline & Dezembro & 1 & $5,9 \%$ \\
\hline & Outubro a janeiro & 2 & $11,8 \%$ \\
\hline & Agosto a dezembro & 3 & $17,6 \%$ \\
\hline & Novembro a dezembro & 3 & $17,6 \%$ \\
\hline & Julho a setembro & 2 & $11,8 \%$ \\
\hline & Dezembro a janeiro & 1 & $5,9 \%$ \\
\hline \multirow[t]{2}{*}{$\begin{array}{l}\text { Os visitantes podem fazer } \\
\text { trilhas sem acompanhamento } \\
\text { de condutores? }\end{array}$} & Não & 17 & $100,0 \%$ \\
\hline & $\begin{array}{c}\text { Para o divertimento dos } \\
\text { turistas }\end{array}$ & 4 & $23,5 \%$ \\
\hline \multirow{3}{*}{$\begin{array}{l}\text { Em sua opinião, para que } \\
\text { serve a atividade de condutor } \\
\text { de visitantes em relação aos } \\
\text { turistas guiados? }\end{array}$} & $\begin{array}{c}\text { Para a educação dos } \\
\text { turistas }\end{array}$ & 4 & $23,5 \%$ \\
\hline & $\begin{array}{l}\text { Para divertimento e } \\
\text { educação dos turistas }\end{array}$ & 8 & $47,1 \%$ \\
\hline & $\begin{array}{l}\text { Para a troca de } \\
\text { experiências }\end{array}$ & 1 & $5,9 \%$ \\
\hline
\end{tabular}

Fonte: Elaborada pela autora. Source: Prepared by the author.

De acordo com os dados obtidos, a maioria $(58,8 \%)$ possui o ensino fundamental como nível de formação, demonstrando baixa escolaridade, confirmando a carência de profissionais com nível superior atuando em atividades físicas de aventura na natureza, e a inexistência de órgãos que regulamentem 0 tipo de formação necessária desses profissionais, demonstrada por Bandeira \& Ribeiro (2015), que ao mesmo tempo ressaltam que a prática é possível, na medida que são produzidos saberes pelos 
envolvidos com o ambiente local que superam os conhecimentos construídos no meio acadêmico, valendo mais quem conheça bem o ambiente e tenha capacidade de percorrer e sobreviver em meio a variados fenômenos naturais.

A maioria (47,1\%), declarou ter menos de 10 anos de experiência como condutor, e em relação aos rendimentos com a atividade, ganham até um salário-mínimo (70,6\%), índice que se aproximou do estudo de Cotes et al., (2018b), cujo resultado foi de $72,2 \%$.

A maioria dos entrevistados $(82,4 \%)$ possui outra forma de obter rendimentos além da atividade de condução de visitantes. Dentre elas, foram citadas diversas outras fontes de renda, tais como: Benefícios governamentais como Bolsa família (5,9\%) e aposentadoria $(5,9 \%)$, e além disso, as ocupações de controlador de microssistema de abastecimento de água $(5,9 \%)$, pedreiro $(5,9 \%)$, cozinheira $(5,9 \%)$, mototaxista $(5,9 \%)$, produtor de artesanato $(11,8 \%)$, vendedor em comércio $(11,8 \%)$, extrativista e produtor de artesanato (5,9\%), extrativista (5,9\%),árbitro de futebol $(5,9 \%)$, criador de galinhas e ajudante em restaurante (5,9\%). Referente a isso, é possível notar que muitas das ocupações praticadas pelos entrevistados além da atividade de condutor, são derivadas da atividade turística existente na comunidade, o que é apontado por Bezerra e Pinto (2018) ao afirmarem que anteriormente ao Turismo de Base comunitária, as principais atividades econômicas da comunidade de Jamaraquá eram a pesca, agricultura e o extrativismo vegetal, que tinham suas técnicas transmitidas através de gerações.

Quando questionados sobre terem feito curso específico de condutor, a maioria $(58,8 \%)$ respondeu que sim, porém identificou-se que uma parcela significativa respondeu que não $(41,2 \%)$, o que vai contra o que está disposto no artigo 13 da Instrução Normativa no 2 do ICMBio, que diz que para os trabalhadores da área de condução de visitantes serem autorizados a prestar o serviço em UC federais, deveriam possuir o curso específico de condutor até doze meses a partir da data de publicação da norma, ouseja, até o mês de maio de 2017 (BRASIL, 2016). Sobre isso, Cotes et al. (2018a) apontam que embora a norma tenha sido criada para regulamentar a condução, o prazo estabelecido foi muito curto para que sejam atendidas as exigências pelos condutores cadastrados, o que deveria afetar o seu cumprimento com a qualidade almejada.

Sobre capacitação na área ambiental ou turística, a maior parte dos entrevistados $(70,6 \%)$ afirmou ter feito, e nessa questão, foram citados alguns dos cursos como: coordenador de comunidade turística $(5,9 \%)$, curso de guia especializado (5,9\%), curso de observação de animais $(5,9 \%)$ e curso de controle de fogo (5,9\%). Jacobson (1992) defende quatro razões para o aprimoramento na formação de condutores: diminuir os impactos na localidade em questão; fortalecer o relacionamento entre o condutor e a comunidade; melhorar a qualidade da experiência para o visitante, e gerar renda para as comunidades locais. Ainda sobre isso, Pereira, Silva e SilvaJunior (2015) e Canto-Silva e Silva (2017) acrescentam que a formação eficaz 
é essencial para que o turismo desenvolva seu potencial de educação, colaborando com a UC visitada.

Em relação ao curso de primeiros socorros, a maioria $(64,7 \%)$ declarou ter feito. É importante observar que a capacitação continuada é incentivada pelo ICMBio, e entre os conteúdos mínimos exigidos na capacitação do condutor de visitantes está o item primeiros socorros e busca e salvamento (BRASIL, 2016). Sobre o assunto, Cassiano et al. (2016) afirmam que o curso de primeiros socorros é essencial na formação de condutores e deve ser apresentado na prática.

A maioria $(82,4 \%)$ declarou falar outro idioma, e sobre o público atendido, apontou que a maioria é formada por turistas brasileiros $(82,4 \%)$.

A respeito do domínio da atividade de condutor, a maioria dos entrevistados $(88,2 \%)$ declarou possuir, e quanto à forma de dar informações aos turistas, a maior parte $(88,2 \%)$ respondeu que faz uma apresentação geral sobre os atrativos durante a trilha.

Ao considerar o período no ano em que aparecem mais grupos de turistas para serem guiados, os inquiridos relataram haver visitação em vários meses, todavia houve a predominância de respostas no intervalo de julho a fevereiro (29,4\%). Na comunidade de Jamaraquá, a visitação pode ser feita durante 0 ano todo, porém, o período de junho a dezembro, é o mais indicado, pois é quando as chuvas diminuem na região, e é possível usufruir das praias, que surgem no rio Tapajós como um atrativo excepcional a mais (BRASIL, 2019).

A maioria (100\%) indica que é obrigatória a presença do condutor nas trilhas para o acompanhamento dos visitantes, o que está de acordo com 0 Art. 5da Instrução Normativa ICMBIO № 2, de 3 de maio de 2016, que fala sobre a obrigatoriedade dos visitantes serem acompanhados pelo condutor nas unidades de conservação, nos ambientes que requerem proteção especial, ou em circunstâncias específicas onde inexistam possibilidades de manejo de impacto ou de controle efetivo de visitação, objetivando proteger o patrimônio natural, histórico, arqueológico e cultural.(BRASIL, 2016).

Quando questionados sobre para que serve a sua atividade de condutor em relação aos visitantes guiados, a maioria dos entrevistados $(47,1 \%)$ respondeu que é para o divertimento e educação dos turistas. Sobre isso, Ribas e Hickenbick (2012) afirmam que condutor de visitantes deve se preocupar com a conservação dos ecossistemas locais, bem-estar das populações envolvidas e a satisfação dos visitantes, promovendo uma sensibilização ecológica e cultural deles, através da educação ambiental e da prática do lazer. Os autores informam também, que quando as técnicas educativas são realizadas de maneira excessiva ou desinteressante, podem levar ao fracasso de um programa de Ecoturismo. 


\section{Considerações finais}

O trabalho do condutor de visitantes é um importante componente para as boas práticas de visitação em Unidades de Conservação.

O objetivo geral desta pesquisa foi demonstrar as características socioeconômicas, acadêmicas e profissionais dos condutores de visitantes da comunidade de Jamaraquá, e teve como objetivos específicos: identificar informações socioeconômicas dos condutores; averiguar dados acadêmicos; conhecer aspectos profissionais e pesquisar a opinião dos entrevistados sobre a atividade que desempenham.

Desse modo, em relação às informações socioeconômicas dos condutores, conclui-se que a maioria dos condutores de visitantes da comunidade de Jamaraquá é do sexo masculino, tem 41 anos ou mais, são casados ou estão em união estável, são nascidos na comunidade e residem em habitação própria.

Quanto aos dados acadêmicos e aspectos profissionais, chegou-se à conclusão de que possuem o ensino fundamental como nível de formação, têm menos de dez anos de experiência como condutor, e ganham com atividade até um salário mínimo, possuindo outras fontes de renda além da condução de visitantes, ligadas em grande parte, de forma direta ou indireta ao turismo na comunidade; possuem curso específico de condutor, de capacitação na área ambiental ou turística e em primeiros socorros; falam outro idioma além do português; atendem turistas brasileiros, cujo fluxo maior de visitação é no intervalo dos meses de julho a fevereiro; possuem domínio da atividade de condutor ,e como forma de mostrar os atrativos, fazem uma apresentação geral durante a trilha, indicando que a sua presença nas trilhas da comunidade é obrigatória, e que a sua atividade serve para o divertimento e a educação dos turistas.

Partindo desta pesquisa, estudos mais aprofundados podem ser feitos no sentido de buscar identificar as deficiências existentes em relação à capacitação dos condutores de Jamaraquá, averiguando, por exemplo, quais indivíduos ainda não possuem cursos específicos de condutor, assim como também, fazendo o levantamento de outros cursos da área turística e ambiental que sejam necessários ao desenvolvimento de um turismo realmente sustentável na comunidade, incluindo a conservação do meio ambiente, o atendimento pleno das necessidades dos comunitários, e dos turistas que visitam o local. Nesse sentido, tem-se a expectativa de que os profissionais que trabalham com políticas públicas voltadas à promoção do Ecoturismo e aqueles que atuam diretamente com a capacitação de condutores de visitantes, enxerguem nesses profissionais uma das grandes oportunidades de desenvolver essa categoria do turismo de maneira plena e responsável na comunidade. 


\section{Referências}

BANDEIRA, M. M., RIBEIRO, O. C. F. Sobre os profissionais da aventura: problemas da atuação na interface esporte e turismo. Licere, v.18, n.3,2015, 116-157.

BEZERRA, G. B. C. B. , PINTO, A. F. F. P. Turismo e reorganização do espaço local: uma análise geográfica acerca da comunidade Jamaraquá, Belterra/Pará. Disponível em: <www.eng2018.agb.org.br > arquivo > downloadpublic>. Acesso em: 02 dez. 2020.

BRASIL. Decreto 73.684 publicado em 20 de fevereiro do ano de 1974. Cria a Floresta Nacional do Tapajós, e dá outras providencias. Diário Oficial da União: pág.1987 col.3, Brasília, DF, 20 fev 1974. Disponível em:<http://legis.senado.leg.br/norma/496324>. Acesso em: 03 dez. 2020.

BRASIL. Lei n. 9.985, de 18 de julho de 2000. Institui o Sistema Nacional de Unidades de Conservação da Natureza e dá outras providências. Brasília, DF. Disponível em: <https://www.planalto.gov.br/ccivil 03/leis/l9985.htm>. Acesso em: 15 fev. 2020.

BRASIL. Ministério do Meio Ambiente. Instituto Brasileiro do Meio Ambiente e dos Recursos Naturais Renováveis. Floresta Nacional do Tapajós: Diagnóstico Rural Participativo. Belterra-PA, 2003.

BRASIL. Ministério do meio Ambiente. Floresta Nacional do Tapajós - Plano de Manejo - Volume I (2004). Disponível em:<https://www.icmbio.gov.br/portal/images/stories/imgs-unidadescoservacao/flona tapajoss.pdf>. Acesso em: 05 jan. 2021.

BRASIL. Ministério do Meio Ambiente. (2005). Diagnóstico da visitação em parques nacionais e estaduais. Brasília: MMA. Disponível em: $<$ http://www.institutobrasilrural.org.br/download/20120220100952.pdf> Acesso em 13 fev. 2021.

BRASIL. Ministério do Meio Ambiente. (2006). Diretrizes para a visitação em unidades de conservação. Brasília: MMA. Disponível em: $<$ https://www.researchgate.net/publication/332199683 Diretrizes para Visitac ao em Unidades de Conservacao > .Acesso em 15 fev. 2021.

BRASIL. Ministério do Meio ambiente. Instituto Chico Mendes de Conservação da Biodiversidade. Instrução Normativa ICMBio nํ 08, de 18 de setembro de 2008. Estabelece normas e procedimentos para a prestação de serviços vinculados à visitação e ao turismo em 52 Unidades de Conservação Federais por condutores de visitantes. Disponível em: $<$ https://www.icmbio.gov.br/portal/images/stories/o-que-somos/in082008.pdf > . Acesso em: 01 de fev. 2021.

BRASIL. Ministério do Turismo. Ecoturismo: orientações básicas. 2ed. Brasília: Ministério do 2010. $<$ http://www.turismo.gov.br/sites/default/turismo/o ministerio/publicacoes/dow nloads publicacoes/Ecoturismo Versxo Final IMPRESSxO .pdf >. Acesso em: 15 fev. 2021 
BRASIL. Ministério da saúde. Conselho nacional de saúde. Comissão nacional de ética em pesquisa. Resolução no196 de 96 - Diretrizes e Normas Regulamentadoras de Pesquisas Envolvendo Seres Humanos. 2013. Disponível em: <http://bvsms.saude.gov.br/bvs/saudelegis/cns/2013/res0466 1212 2012.ht ml>Acesso em: 10 fev. 2021.

BRASIL. Ministério do Turismo. Portaria № 27 de 30 de janeiro de 2014. Estabelece requisitos e critérios para o exercício da atividade de Guia de Turismo e dá outras providências. Disponível em: $<$ https://www.legisweb.com.br/legislacao/?id=265144 >. Acesso : 02 fev. 2021.

BRASIL. Ministério do Meio ambiente. Instituto Chico Mendes de Conservação da Biodiversidade. INSTRUÇÃO NORMATIVA ICMBIO № 2, DE 3 DE MAIO DE 2016. Dispõe sobre normas e procedimentos administrativos para autorização de uso para a prestação do serviço de condução de visitantes em unidades de conservação federais, conforme as informações contidas no processo $\mathrm{n}^{\circ}$ 02070.001887/2012-05. Disponível em: $<$ https://www.icmbio.gov.br/cepsul/images/stories/legislacao/Instrucao normat iva/2016/in icmbio 22016 exerc\%c3\%adcio atividade conducaovisitantes ucs.pdf >. Acesso em: 04 fev. 2021.

BRASIL. Instituto Chico Mendes de Conservação da Biodiversidade. Turismo de base comunitária em unidades de conservação federais: caderno de experiências (2019a). Disponível em: $<$ https://www.icmbio.gov.br/portal/images/stories/comunicacao/downloads/turi smo de base comunitaria em ucs caderno de experiencias.pdf>. Acesso em: 15 fev. 2021.

BRASIL. Ministério do Meio Ambiente. Plano de Manejo - Floresta Nacional do Tapajós (2019b). Disponível em: $<$ https://www.icmbio.gov.br/portal/images/stories/plano-de-

manejo/plano de manejo flona do tapaj\%C3\%B3s 2019 vol1.pdf >. Acesso em 20 fev. 2021.

BRASIL. Ministério do meio Ambiente. Instituto Chico Mendes de Conservação da Biodiversidade. Parques e Florestas nacionais - Floresta nacional do Tapajós. Santarém, 2021. Disponível em: $<$ https://www.icmbio.gov.br/flonatapajos/guia-do-

visitante\#: :text=As\%20comunidades\%20e\%20Aldeias\%20est\%C3\%A3o,\%2 C\%20Para\%C3\%ADso\%2C\%20Jutuarana\%2C\%20ltapuama\%2C>. Acesso em : 27 de jan. 2021.

BOGGIANI, P. C. A importância dos condutores de visitantes na divulgação das Geociências em unidades de conservação. Terra e Didatica, Campinas, SP, v. 14, n. 4, p. 463-466, 2018. DOI:

CANTO-SILVA, C. R., CUNHA, A. M., BAZOTTI, L. S. \& NASCIMENTO, C. A. (2015). Formação e Organização de Condutores Ambientais Locais: Estratégias de Desenvolvimento do Turismo Sustentável em Unidades de Conservação Gaúchas. Anais do VII Seminário Brasileiro sobre Áreas Protegidas e Inclusão Social - SAPIS e Encontro Latino Americano sobre Áreas Protegidas e Inclusão Social - ELAPIS, 2015. Florianópolis, 2015. 
Disponível em: <https://sapiselapis2015.paginas.ufsc.br/2015/11/18/anais-dovii-sapis-e-ii-elapis/>. Acesso em: 09 fev. 2021.

CANTO-SILVA, C. R., SILVA, J. S. Panorama da visitação e da condução de visitantes em Parques brasileiros. Revista Brasileira de pesquisa em Turismo, v. 11, n. 2, p. 347-364, 2017.

CASSIANO, A.M.; SILVA, D.S.; SEVERIAN, B.A.; LOPEZ-RICHARD, V. Desafíos para la capacitación y acreditación de guías en Unidades de Conservación: Núcleo Picinguaba del Parque Estatal Serra do Mar, Sao Paulo, Brasil. Estudios y Perspectivas en Turismo (En Línea), v. 25, p. 483-501, 2016.

CASTILLO, D.; AREVALO, J.; HERRERA, F.; RUIZ, C.; ROJAS, R.; RENGIFO, E.; VAISBERG, A.; LOCK, O.; LEMESRE, J.-L.; GORNITZKA, H.; SAUVAIN, M. Spirolactoneiridoids might be responsible for the antileishmanial activity of a Peruvian traditional remedy made with Himatanthus sucuuba (Apocynaceae). Journal of Etnopharmacology, n. 112, p. 410-414, 2007.

CEBALLOS-LASCURÁIN, H. O ecoturismo como um fenômeno mundial. In: LINDBERG, K., HAWKINS, D. E. Ecoturismo: um guia para planejamento e gestão. São Paulo: SENAC,2002.

COTES, M.; SALLES, W.N.; SCHIAVETTI, A.; NASCIMENTO, J.V. (2018a) Necessidades formativas de condutores de visitantes em Parques Nacionais. Revista Brasileira de Ecoturismo, São Paulo, v.10, n.4, nov 2017/jan 2018, pp.892-918.

COTES M., SALLES W.N., BRASIL V.Z., IHA T., SCHIAVETTI A., NASCIMENTO, J.V. (2018b) Perfil de condutores de trilhas de longa duração em parques nacionais brasileiros. R. bras. Ci. e Mov; v.26, n.1, 2018, p.167177.

CUNHA, A. M.,BAZOTTI, L. S.,CANTO SILVA, C. Formação de monitores/condutores e educação ambiental - estratégias de desenvolvimento do turismo sustentavel nas UCs do RS.Fólio - Revista Científica Digital 2016; v. 17, n. 1:213-229.

DRUMMOND, J. A., FRANCO, J. L. A.; OLIVEIRA,D. Uma análise sobre a história e a situação das unidades de conservação no Brasil. In: GANEM, R.S. (Ed.) Conservação da Biodiversidade: Legislação e Políticas Públicas, $2010 . \quad$ pp.341-385. Disponível em: $<$ https://www.researchgate.net/publication/303538670>. Acesso em: 15 jan. 2021.

ESPÍNOLA, R.S.; CASTRO, V.M. Ecoturismo e gestão participativa em Áreas Protegidas: o caso da Floresta Nacional do Tapajós (PA). Revista Brasileira de Ecoturismo, São Paulo, v.5, n.2, mai/ago-2012, pp.281-296.

FERRAZ, I. D. K. , SAMPAIO, P. T. B. Métodos simples de armazenamento das sementes de Andiroba (Carapa guianensisAubl. e Carapa proceraD.C. Meliaceae). Acta Amaz., Manaus, v. 26, n. 3, p. 137-144, Sept. 1996. Disponível em: <http://www.scielo.br/scielo.php?script=sci arttext\&pid=S004459671996000300137\&lng=en\&nrm=iso >. Acesso em: 11 fev. 2021. 
FONSECA, J. J. S. Metodologia da pesquisa científica. Fortaleza: UEC, 2002.

GIL, A.C. Métodos e técnicas de pesquisa social. São Paulo: Atlas, 2006.

IKEMOTO, S. M.; MORAES, M. G.; COSTA, V.C. Avaliação do potencial interpretativo da trilha do Jequitibá, Parque Estadual dos Três Picos, Rio de Janeiro. Soc. nat. (Online), Uberlândia, v. 21, n. 3, p. 271-287, Dec. 2009.

JACOBSON, S.K. El desarollo de un programa de entrenamiento para guias de ecoturismo en Tortuguero, Costa Rica. In: HAM, S.H. (Ed.) Interpretacion ambiental: una guia practica para gente con grandes ideias y presupuestos pequenos. Colorado: North American Press, 1992. p. 160- 162.

INEA. Instituto de Estudos Integrados Cidadão da Amazônia. Relatório Estratégico da Comunidade de Jamaraquá, 2012.

KINKER, S. Ecoturismo e Conservação da natureza em Parques Nacionais. Campinas: Papirus, 2002.

MALDONADO, C. 20090 turismo rural comunitário na América Latina: gênesis, características e políticas. In: BARTHOLO, R.; SANSOLO, D.G.; BURSZTYN, I. (Org.). Turismo de Base Comunitária: diversidade de olhares e experiências brasileiras. Rio de Janeiro: Letra e Imagem, pp. 25-44, 2009.

MOREIRA, J. C.; BURNS, R. C. Turismo, Manejo De Uso Público e a percepção dos visitantes: coleta de dados na Floresta Nacional Do Tapajós (Pará). Anais do VIII CBUC - Trabalhos Técnicos 2015. Disponível em: <https://www.researchgate.net/publication/286936403>. Acesso em: 21 jan. 2021.

NASCIMENTO, C. A., CANTO-SILVA, C. R. C., MELO, I. B. N. \& MARQUES, S. C. M. A regulamentação da atividade de condução de visitantes nos Sistemas Estaduais de Unidades de Conservação do Brasil. Revista Brasileira de Pesquisa em Turismo, 2016,v. 10, p. 516-532.

NEIMAN, Z. A educação ambiental através do contato dirigido com a natureza. (Tese Doutorado em Psicologia Experimental) - Universidade de São Paulo, Instituto de Psicologia, São Paulo: p.234. 2007. Disponível em: https://www.teses.usp.br/teses/disponiveis/47/47132/tde-19062008085321/publico/Neiman do.pdf. Acesso em: 13 de jan. 2021.

ORGANIZAÇÃO MUNDIAL DO TURISMO (OMT). 2018. Sustainable Development of Tourism. Disponível em: <http://sdt.unwto.org/content/about-us-5>. Acesso em: 06 fev. 2021.

PEREIRA, A. I. DE A.; SILVA, F. J. DE L.; SILVA JÚNIOR, J. M. DA. Influência dos cursos de capacitação do Projeto Golfinho Rotador na atuação profissional dos condutores de ecoturismo em Fernando de Noronha (PE): uma contribuição a sustentabilidade turística local. Revista Brasileira de Ecoturismo (RBEcotur). v. 8, n. 1, 28 fev.2015.

PINHEIRO, R. M.; CASTRO, G. C. de; SILVA, H. H.; NUNES, J. M. G. Comportamento do consumidor e pesquisa de mercado. 3. ed. Rio de Janeiro: Editora FGV, 2006. 
PRADO, M. V. P., ANDRADE, J. R. L., FACCIOLI, G. G. Turismo sustentável e capacidade de carga dos atrativos turísticos no município de Canindé do São Francisco/SE: Uma reflexão dos aspectos metodológicos. Anais... Indaiatuba: Anppas, 2004. 11 p. Disponível em: $<$ http://www.anppas.org.br/encontro anual/encontro2/GT/GT15/marta virginia .pdf>. Acesso 13 de jan 2021.

RIBAS LCC, HICKENBICK C. O Papel de Condutores Ambientais Locais e de Cursos de Capacitação no Ecodesenvolvimento Turístico e as Expectativas Sociais no Sul do Brasil. Turismo em Análise, v.23, n.1, 2012, p.143-165.

SACHS, Ignacy. Desenvolvimento: includente, sustentável e sustentado. Rio de Janeiro: Garamond, 2008.

SILVA, A. S. ; SILVA, A. P. ; VIANA, I. G. S. . A Influência do Turismo de Base Comunitária na Dinâmica Espacial da Comunidade de Jamaraquá, Flona Tapajós - Belterra - PA. In: ENANPPAS 2017 - VIII ENCONTRO NACIONAL DA ASSOCIAÇÃO NACIONAL DE PÓS-GRADUAÇÃO E PESQUISA EM AMBIENTE E SOCIEDADE, 2017, Natal -RN. Anais do ENANPPAS 2017. Disponível em : <http://www.enanppas2017.com.br/> Acesso: 05 dez 2020

SILVA, J.H. \& MAIA, F. B. A. (2011). Organização local e gestão participativa o turismo em unidades de conservação: a difícil tarefa de integração no Parque Nacional do Catimbau (PE). Caderno Virtual de Turismo. Rio de Janeiro, v.11, n.1, pp. 36-48, abr.

SILVA, M. J. Soares da; SOUSA, A. M. P.; SILVA, A. C. F.; RODRIGUES, D. S. Levantamento de famílias da Floresta Nacional do Tapajós, Pará. In: 2o Seminário de Pesquisa Científica da Floresta nacional do Tapajós. Anais do II Seminário de Pesquisa Científica da Floresta nacional do Tapajós. ICMBio, $2014 . \quad$ p. 235-242. Disponível em: $<$ https://www.icmbio.gov.br/flonatapajos/images/stories/destaques/anais II se minario de pesquisas.pdf>.Acesso em: 20 jan. de 2021.

UNEP. Towards a Green Economy: Pathways to Sustainable Development and Poverty Eradication - A Synthesis for Policy Makers. Nairobi: Unep, 2011. Disponível

em:<https://sustainabledevelopment.un.org/content/documents/126GER synt hesis en.pdf>. Acesso em: 03 dez. 2020.

Veríssimo, A., ROLLA, A., Vedoveto, M. FUtAdA, S. de M. Áreas Protegidas na Amazônia Brasileira: avanços e desafios Belém/São Paulo: Imazon e ISA, 2011.Disponível em: <https://imazon.org.br/areas-protegidasna-amazonia-brasileira-avancos-e-desafios-2/>. Acesso em: 15 de fev. 2021

WESTERN, D. (2002). Como definir o Ecoturismo. In: LINDBERG, K; HAWKINS, D. E. Ecoturismo: um guia para planejamento e gestão. São Paulo: SENAC.

WORLD WILDLIFE FUND (WWF) 2001. Guidelines for community-based ecotourism development. Disponível em: $<$ https://wwf.panda.org/wwf news/?12002/Guidelines-for-Community-basedEcotourism-Development>. Acesso em: 05 fev. 2021. 
Simone Lobato Ferreira da Cruz: Instituto Federal de Educação, Ciência e Tecnologia do Pará, Santarém, PA, Brasil.

E-mail: simonelobatocruz@hotmail.com

Link para o currículo Lattes: http://lattes.cnpq.br/2143202026937348

Data de submissão: 08 de março de 2021

Data de recebimento de correções: 01 de maio de 2021

Data do aceite: 01 de maio de 2021

Avaliado anonimamente 